\title{
Consolidação da paz numa perspetiva crítica: 0 caso de Timor-Leste
}

A Critical Approach to Peacebuilding: The Case of Timor-Leste

Consolidation de la paix d'un point de vue critique: le cas de Timor-Leste

Maria Raquel Freire e Paula Duarte Lopes

\section{(Q) OpenEdition}

\section{Journals}

Edição electrónica

URL: http://journals.openedition.org/rccs/5653

DOI: $10.4000 /$ rccs. 5653

ISSN: 2182-7435

\section{Editora}

Centro de Estudos Sociais da Universidade de Coimbra

\section{Edição impressa}

Data de publição: 1 Setembro 2014

Paginação: 05-20

ISSN: 0254-1106

\section{Refêrencia eletrónica}

Maria Raquel Freire e Paula Duarte Lopes, « Consolidação da paz numa perspetiva crítica: O caso de Timor-Leste », Revista Crítica de Ciências Sociais [Online], 104 | 2014, colocado online no dia 23 setembro 2014, criado a 19 abril 2019. URL : http://journals.openedition.org/rccs/5653 ; DOI : $10.4000 /$ rccs. 5653 


\section{MARIA RAQUEL FREIRE, PAULA DUARTE LOPES}

\section{Consolidação da paz numa perspetiva crítica: O caso de Timor-Leste}

Partindo do debate sobre intervencionismo e em particular discutindo a abordagem das Nações Unidas em termos de manutenção e construção da paz, este artigo adota uma leitura crítica de ações e reações, discurso e prática, bem como de terminologias adotadas e praticadas, sem consensualização quanto a conteúdos. $O$ artigo analisa em particular a intervenção das Nações Unidas em Timor-Leste procurando identificar os principais contributos e limites da organização na promoção da paz, segurança e estabilidade no país. O texto conclui com o entendimento de que é necessário procurar equilíbrios na gestão destes processos complexos de intervenção, partindo do reconhecimento do contributo que estas presenças externas pode efetivamente significar em termos de consolidação da paz, embora questionando abordagens, e sugerindo uma melhor articulação entre instrumentos e práticas na operacionalização de mandatos.

Palavras-chave: consolidação da paz; construção da paz; manutenção da paz; Organização das Nações Unidas (ONU); resolução de conflitos; Timor-Leste.

Os processos de intervenção externa em contextos de violência e/ou pós-violência têm sido analisados sob perspetivas diferenciadas. Em termos teóricos, as abordagens mais tradicionais de resolução de conflitos, centradas em modelos problem-solving e com uma componente neoliberal e institucional forte, assente em lógicas top-down, têm-se confrontado com as perspetivas mais críticas, numa lógica mais interpretativa e de questionamento das bases do modelo neoliberal, dando maior atenção às práticas locais numa lógica de articulação e diferenciação entre o tradicional top-down e o menos consensual bottom-up. A intervenção de organizações internacionais, como as Nações Unidas (NU), ou mesmo organizações de caráter regional, que se associam ao modelo onusiano, em que encontram legitimidade, tem permitido a perpetuação de um modelo de intervenção muito centrado no desenvolvimento de projetos a nível institucional, nem sempre dando a devida atenção a outras áreas de atuação. Esta abordagem favorece a promoção de uma 'paz institucional', que não integra muitas 
vezes como dimensões centrais da sua consolidação e sustentabilidade o desenvolvimento de cultura e práticas políticas democráticas, por exemplo, em contextos onde estas são muitas vezes inexistentes. Além do mais, esta abordagem à paz descura em grande medida a articulação com o nível local, limitando-a a contactos com as elites, que muitas vez traduzem a lógica do mandato e acabam por contribuir para a reprodução de práticas sociais ao nível dessas elites numa lógica imitativa, evitando desse modo o desenvolvimento de dinâmicas integradas entre atores e práticas externas e contextos e agentes locais, informadas por dinâmicas de inclusão e cariz emancipatório.

Partindo do debate sobre intervencionismo e em particular discutindo a abordagem das Nações Unidas em termos de manutenção e construção da paz, este artigo introdutório ao número especial sobre 'Consolidação da paz em Timor-Leste' adota uma leitura crítica de ações e reações, discurso e prática, bem como de terminologias adotadas e praticadas, sem consensualização quanto a conteúdos. $\mathrm{O}$ artigo analisa em particular a intervenção das Nações Unidas em Timor-Leste, procurando identificar os principais contributos e limites da organização na promoção da paz, segurança e estabilidade no país como contexto dos números que se seguem. O texto conclui com o entendimento de que é necessário procurar equilíbrios na gestão destes processos complexos de intervenção, partindo do reconhecimento do contributo que estas presenças externas pode efetivamente significar em termos de consolidação da paz, embora questionando abordagens, e sugerindo uma melhor articulação entre instrumentos e práticas na operacionalização de mandatos.

Entendendo que a doutrina onusiana em matéria de intervenção evoluiu consideravelmente nos últimos anos no sentido de incluir dimensões menos tradicionais na agenda, como o reconhecimento de que práticas de consolidação da paz devem acompanhar os instrumentos de manutenção da mesma numa lógica integrada; de que o envolvimento da dimensão local nas suas diversas facetas deve ser tido em especial consideração, evitando sentimentos de alienação e promovendo corresponsabilização nos processos (ver Tschirgi, neste volume); e de que apesar dos muitos instrumentos à disposição das NU nem sempre a sua utilização revela uma dinâmica pragmática de resposta às necessidades efetivas, este texto analisa o caso específico de Timor-Leste como ilustrativo de alguns destes desajustes e de como, através de posturas de maior ou menor resistência e acomodação, os contextos locais refletem esta necessidade de uma resposta integrada para a construção de uma paz também ela integrada. 


\section{Intervenção externa: manutenção e construção da paz}

Os debates em torno do intervencionismo global têm ganho novo dinamismo face aos desafios crescentes que surgem resultantes de novos contextos, de novos atores, e mesmo de novas práticas doutrinárias. Apesar da abrangência que estes debates têm assumido, e não pretendendo uma identificação exaustiva dos mesmos, assinalamos aqui três ordens de ideias que nos parecem fundamentais para esta reflexão. Primeiro, em termos teóricos, e como referido acima, as abordagens mais tradicionais de resolução de conflitos, assentes em pressupostos neoliberais como a matriz dominante caraterizadora das intervenções e face à qual os resultados devem ser mensurados, bem como prosseguindo pressupostos teóricos do realismo onde as dinâmicas de poder dominam os debates (Doyle e Sambanis, 2006), têm sido desafiadas por perspetivas mais críticas, assentes em quadros de análise mais inclusivos e que interpretam lógicas de poder não apenas numa ótica de soma nula e de ganhos relativos no posicionamento internacional, mas nas suas implicações mais profundas ao nível das configurações sociais e políticas em ambos os planos interno e externo (ver Tschirgi, neste volume). Quadros de emancipação, políticas de equidade, práticas inclusivas e abordagens estruturais às questões centrais são algumas das linhas diferenciadoras destas abordagens. O distanciamento do quadro neoliberal dominante é, deste modo, prosseguido, trazendo a discussão a necessidade de reformulação de matrizes orientadoras dos processos de intervenção, para que lógicas de dominação deem lugar a lógicas de inclusão, e políticas de imposição deem lugar a políticas emancipatórias. Este quadro normativo reflete-se no debate sobre estratégias marcadamente top-down, cujo centro de atuação são os decisores e as elites políticas, e outras de natureza bottom-up, incidindo essencialmente em atores locais e no seu contributo para dinâmicas de construção da paz (Paris, 1997; Bellamy e Williams, 2004; Paris e Sisk, 2009), entendendo estes como agentes por excelência destes processos dado o historial associado à emergência da violência, às formas tradicionais de lidar com esta e a um conhecimento mais profundo de procedimentos e práticas relativos a especificidades locais em matéria diversa - política, económica, social e cultural -, que são cruciais a uma resposta mais adequada às necessidades, bem como às expetativas.

Segundo, em termos concetuais, os debates têm apontado para o significado dos 'rótulos' associados às intervenções, classificando-as, entre outros, como de manutenção da paz, construção da paz, consolidação da paz, promoção da paz, quanto aos seus objetivos; definindo esta paz como positiva ou negativa por relação à forma como estes objetivos são operacionalizados; classificando os contextos da intervenção como falhados ou frágeis; 
e medindo o sucesso das intervenções através de métricas diferenciadas. O debate concetual é intenso, havendo dissensão sobre 'rótulos' e mais ainda relativamente aos conteúdos associados às diferentes rotulagens (Fortna e Howard, 2008; Cottey, 2008; Woodhouse e Ramsbotham, 2005; O'Neill e Rees, 2005; Bures, 2007; e ainda Tschirgi, neste volume). Esta falta de consensualização na linguagem utilizada, quer nos meios académicos quer nos meios políticos, tem implicações sérias em termos de aplicação prática no terreno e de como os meios devem ser operacionalizados na busca dos fins definidos. As NU têm feito um esforço crescente de definição concetual, visível em particular desde a publicação do documento Uma agenda para a paz (Boutros-Ghali, 1992), de modo a clarificar a terminologia usada, embora nem sempre seja fácil encontrar consensos a nível político. De qualquer modo, por exemplo o Relatório Brahimi (NU, 2000) estabelece de forma clara a necessidade de adaptação de mandatos de intervenção externa para além dos alinhamentos políticos tradicionais, incluindo segurança humana, medidas de consolidação de confiança, acordos de partilha de poder, apoio eleitoral, fortalecimento do Estado de direito e desenvolvimento económico e social (Ramsbotham et al., 2005; Doyle e Sambanis, 2006; Duffield e Wadell, 2004). Estes princípios são consolidados com a Doutrina Capstone (NU, 2008). Apesar de uma agenda ainda muito centrada numa paz institucional, este modelo de leitura mais inclusivo tem sido fundamental na readaptação doutrinária e em termos de práticas das Nações Unidas. Documentos mais recentes, como o relatório do Secretário-Geral sobre Peacebuilding in the aftermath of conflict (NU, 2009) ou o relatório do Peacebuilding Support Office sobre Operationalizing National Ownership (Machold e Donais, 2011), são demonstrativos da mudança gradual que tem vindo a ser implementada. Além de refletirem o quadro referencial de intervenção das Nações Unidas, estes documentos assinalam a necessidade de reconhecer as especificidades dos contextos locais de intervenção, a responsabilização e ownership dos processos de intervenção a nível local e o diálogo inclusivo, como partes integrantes de um todo complexo que resulta dos processos de intervenção externa.

E por fim, numa abordagem mais empírica, as políticas e motivações subjacentes a todo o processo complexo de desenho e tomada de decisão, as burocracias envolvidas, os interesses de determinados Estados ou partes interessadas, a autonomia, a doutrina e a implementação no terreno de políticas e práticas têm também sido objeto de estudo. A interligação entre a doutrina de intervenção e a operacionalização da mesma em contextos diferenciados tem conferido às análises mais teóricas e concetuais uma dimensão concreta de aplicação, que tem contribuído para o enriquecimento 
dos debates (ver Bellamy, neste volume). A própria evolução doutrinária no quadro das Nações Unidas reflete lições aprendidas e procura incorporar a necessidade de políticas e práticas mais estruturais nas suas abordagens. No entanto, e apesar desta evolução em matéria doutrinária merecer destaque, não deve ser esquecido que da doutrina à prática há ainda um longo caminho a percorrer, como o caso de Timor-Leste ajudará aqui a demonstrar.

Os processos de construção e consolidação da paz são, assim, processos imbuídos de grande complexidade, seja relativamente aos atores que envolvem, seja nos objetivos que definem, seja quanto aos instrumentos usados, seja ainda na interligação entre dinâmicas locais, nacionais e mesmo regionais ou internacionais. Neste número especial os autores partilham de uma abordagem crítica ao intervencionismo, questionando as formas mais tradicionais de resolução de conflitos pela exclusão de dinâmicas associadas a discurso e significado, que são aqui entendidas como fundamentais na compreensão das dimensões mais profundas destes processos. Também é aqui claro que manutenção da paz e construção da paz são conceitos interdependentes e mutuamente constitutivos. Apesar de a manutenção da paz poder assumir contornos precisos em termos do que um mandato possa definir, a inclusão de vetores associados à construção da paz é cada vez mais presença na formulação dos mesmos, seguindo um entendimento já refletido a nível doutrinal, de que são necessárias respostas multidimensionais a problemas e desafios também eles com cariz diverso.

\section{Da teoria à prática: as Nações Unidas em Timor-Leste'}

Esta secção analisa brevemente o período compreendido entre o Referendo de 1999 e a restauração da independência de Timor-Leste em 2002, e ainda entre esta e a saída das Nações Unidas do país em dezembro de 2012, diminuindo consideravelmente a sua presença a um gabinete político, com uma agenda orientada para o desenvolvimento social e económico e discutindo

\footnotetext{
${ }^{1}$ Esta secção segue o trabalho desenvolvido pelas autoras e outros colegas no âmbito de um projeto de investigação financiado pela Fundação para a Ciência e a Tecnologia (FCT) intitulado "Consolidação da paz e a sua sustentabilidade: as missões da ONU em Timor-Leste e a contribuição de Portugal", que decorreu entre 2011 e 2014 (PTDC/CPJ-CPO/115169/2009 - FCOMP-01-0124-FEDER-014433), tendo resultado também na publicação de Maria Raquel Freire (org.), intitulada Consolidação da paz e a sua sustentabilidade: as missões da ONU em Timor-Leste e a contribuição de Portugal (Coimbra: Imprensa da Universidade de Coimbra, no prelo). A presença das NU em Timor-Leste entre 1999 e 2012 ficou marcada por mandatos distintos das diferentes missões: a United Nations Mission in East Timor (UNAMET), em 1999; a United Nations Transitional Administration in East Timor (UNTAET), entre 1999-2002; a United Nations Mission of Support to East Timor (UNMISET), entre 2002-2005; a United Nations Office in East Timor (UNOTIL), entre 2005-2006 e a United Nations Integrated Mission in East Timor (UNMIT), entre 2006-2012.
} 
o contexto geral no âmbito do qual os diferentes contributos deste número especial se inserem. Face aos debates e desafios acima expostos, pretende-se com este mapeamento perceber as implicações da intervenção externa das Nações Unidas em Timor-Leste, que tipo de paz foi promovido ao longo da presença das diferentes missões e que lições podem ser retiradas de um processo de intervenção complexo, mas lido genericamente como bem-sucedido.

O Referendo que decidiu o futuro de Timor-Leste após anos de ocupação teve lugar em agosto de 1999. As Nações Unidas apoiaram a consulta popular através da United Nations Mission in East Timor (UNAMET), cuja tarefa principal era assegurar um contexto político favorável ao livre exercício de voto, de forma participada, transparente e informada (NU 1999a, 1999b). De um total de 98\% de votos registados, 78,5\% foram favoráveis à independência (Governo de Timor-Leste, s/d). No entanto, o anúncio dos resultados gerou tensões que se intensificaram, gerando violência liderada por grupos de milícias pró-Indonésia que contestavam os resultados. A extensão do mandato da UNAMET até 30 de novembro de 1999 e o reforço deste face à necessidade de resposta premente perante a instabilidade crescente revelaram-se limitados e acabaram por forçar a retirada da missão para a Austrália. A degradação das condições no território era clara e a violência sobrepôs-se à agenda internacional de apoiar a independência de Timor-Leste.

Como resposta à violência, o Conselho de Segurança das Nações Unidas (CSNU) aprovou o envio de uma força internacional liderada pela Austrália - International Force for East Timor (INTERFET) - que inicia a sua intervenção a 20 de setembro de 1999 (NU, 1999c). A atuação da INTERFET e a decisão da Assembleia Consultiva na Indonésia de reconhecimento dos resultados do referendo contribuíram para a gradual estabilização da situação. É neste contexto de viragem que a United Nations Transitional Administration in East Timor (UNTAET) chega ao território. Na bagagem, um mandato denso: criação das instituições do Estado timorense e de condições para que este assuma a responsabilidade de condução do território à independência. A UNTAET tem mandato pleno em termos dos poderes executivo, legislativo e judicial na administração do território, o que lhe confere uma enorme responsabilidade no processo de consolidação de estabilidade e de construção do Estado.

A UNTAET promoveu a criação de instituições de governação centralizadas, a serem legitimadas através da realização de eleições e de acordo com princípios de Estado de direito e respeito por direitos e liberdades fundamentais, em linha com o modelo neoliberal onusiano. Apesar da densidade 
das tarefas a desenvolver, o mandato inicial da UNTAET foi estabelecido pelo período de um ano apenas, acabando por ser estendido durante cerca de dois anos e meio. Neste período, a estrutura política na base do atual Estado timorense foi criada (UNTAET, 2002; ver também Tansey, 2009; DeShaw Rae, 2009; Smith, 2003; Beauvais, 2001; e ainda Matsuno, neste volume). No processo, o envolvimento dos timorenses deve ser sublinhado, bem como a dinâmica de 'timorização' que foi ganhando espaço, e que visava a transferência gradual de competências para os timorenses (entrevista a Ramos-Horta, 2012). O envolvimento local no desenho de algumas estruturas políticas e na articulação com práticas informais a nível judicial, por exemplo, revelou-se fundamental na gestão de equilíbrios por vezes precários num contexto ainda frágil. Demonstrou ainda que a intervenção não tem de ser absolutamente top-down, acautelando maior inclusão da dimensão local na definição de processos estruturantes.

Entendendo este como um mandato difícil num contexto também ele difícil, é bastante consensual o reconhecimento de que a UNTAET desempenhou um papel fundamental na criação do Estado timorense (para mais informação sobre a construção do Estado e da nação timorenses, ver Mendes, neste volume). A coincidência das agendas das NU e dos governantes timorenses contribuiu para este resultado positivo. No entanto, não deve deixar de ser referido o facto de a atenção das NU estar essencialmente voltada para as necessidades do Estado na sua dimensão institucional, promovendo uma 'paz como governação', ou seja, uma paz essencialmente institucional e técnica. Aqui reside uma das críticas mais importantes à atuação das NU ao descurar o desenvolvimento de uma paz estrutural, significando uma paz multidimensional e inclusiva. Invisibilizar dinâmicas locais pode levar a formas de resistência, que mesmo que controladas em determinados contextos, podem a seu tempo revelar-se desestabilizadoras. Assim tem acontecido em diferentes cenários de intervenção. Assim aconteceu também em Timor-Leste, apesar de a apropriação de várias dimensões do processo a nível local ter permitido uma excecionalidade especial neste caso em particular.

A nova Constituição foi aprovada em março de 2002, o treino da nova polícia e das Forças Armadas foi iniciado, os refugiados começaram a regressar às suas casas e Xanana Gusmão foi eleito o primeiro Presidente da República de Timor-Leste, a 14 de abril, abrindo assim caminho à independência formal - e a consequente passagem de poderes e competências das NU para as autoridades timorenses -, no dia 20 de maio de 2002. A restauração da independência significa um novo contexto onde a presença das NU vai ser ajustada, com especial enfoque no processo de transição a nível da administração e das 
instituições de segurança. A nova missão das NU que substitui a administração transitória, a United Nations Mission of Support in East Timor (UNMISET), acabou por se revelar limitada no exercício de capacitação local, essencialmente ao nível da formação de recursos humanos. Uma leitura distante da situação nas suas dimensões a nível estrutural, particularmente em termos das dificuldades económicas e sociais sentidas e das tensões a nível político, levou à decisão de alteração do formato da presença das NU em 2005, reduzindo-a para o United Nations Office in East Timor (UNOTIL) (NU, 2005), que prossegue este objetivo de capacitação como central. Contudo, os problemas de violência que surgiram em finais de 2006, envolvendo forças de segurança e revelando incapacidade de resolução de problemas estruturais de forma preventiva (ver Matsuno, neste volume), forçaram uma intervenção conjunta de forças australianas, portuguesas, malaias e neozelandesas. Após a estabilização da situação, o então Primeiro-Ministro José Ramos-Horta solicita às NU o envio de uma missão integrada (NU, 2006a), demonstrando o entendimento de que a situação exigia uma resposta mais completa que ligasse efetivamente os vários elementos da intervenção através de medidas coordenadas entre as agências das NU, com outras representações externas e com as autoridades locais, e consolidadas na forma de atuação, com linhas de prioridade claramente identificadas.

A United Nations Integrated Mission in Timor-Leste (UNMIT) inicia funções em agosto de 2006 (NU, 2006b) e permanece no país até dezembro de 2012. As suas atividades incluíam assegurar a ordem pública, reforçar o funcionamento das instituições do Estado e treinar as Forças de Defesa e da Polícia Nacional. Com a aproximação de eleições parlamentares em 2007, a questão eleitoral tornou-se também central na agenda. Durante dois anos viveu-se um período político e social conturbado que incluiu as tentativas de assassinato do então Primeiro-Ministro José Ramos-Horta e do Presidente Xanana Gusmão. Mas gradualmente a normalização retornou e o processo de consolidação institucional foi prosseguido num contexto local estabilizado. As eleições de 2012, parlamentares e presidenciais, decorreram de acordo com os padrões internacionalmente definidos para estes processos, e desde o período de violência registado em 2008 não se verificaram novos incidentes de violência generalizada nem localizada. A UNMIT concluiu o seu mandato em dezembro de 2012, e foi substituída por uma presença política diminuída, com um enfoque claro em questões económicas e de desenvolvimento. Estas foram identificadas como parte das questões fundamentais a dar resposta para a consolidação da paz, que devem ser enquadradas numa agenda mais inclusiva e de promoção de paz estrutural. De facto, como afirma Carothers (apud Brown, 2011: 21), 
“é extraordinariamente reducionista, mesmo 'mecanicamente irrespirável' considerar que a comunidade política de um estado ou nação podem ser simplesmente identificados como as instituições-chave do governo, por mais importantes que estas sejam".

O modelo institucional de orientação neoliberal, seguindo uma lógica top-down, onde as decisões são tomadas de acordo com linhas tecnicistas de governação e, em muitos casos, de forma distanciada das realidades locais, contribuiu para os limites identificados. As dinâmicas em Timor-Leste revelaram uma aplicação diferenciada do modelo e mesmo uma apropriação local dos processos, revertendo em alguns momentos a lógica top-down, e permitindo que esta assumisse uma perspetiva bottom-up. Talvez um dos exemplos mais significativos tenha sido o processo de adoção da Constituição e o envolvimento ativo dos timorenses no mesmo através de consultas à população a nível distrital e de ajustes, mesmo que limitados, ao texto constitucional decorrentes destas. Além do mais, o sistema de governo inicialmente proposto pelas Nações Unidas, o modelo presidencialista, acabou por ser redefinido no sentido de evitar que as lideranças fortes herdadas do período da resistência se pudessem tornar em elementos que obstaculizassem os processos democráticos. A proposta timorense, que hoje vigora no país, foi a de um sistema semipresidencialista, acautelando a gestão necessária de diferenciais em contextos de democracia governativa. Apesar de dificuldades na operacionalização de uma abordagem mais inclusiva das realidades locais e de maior partilha de responsabilidades, no caso de Timor-Leste, a presença ativa dos timorenses ao longo do processo foi fundamental no sentido de assegurar a inclusão de especificidades entendidas como essenciais à articulação entre a presença externa e o desenvolvimento interno do próprio Estado (Freire, no prelo).

Relativamente à paz técnica resultante do enfoque institucional subjacente à atuação das Nações Unidas nas suas diversas missões, a UNMIT foi a missão que melhor tentou responder a este desafio, incluindo na sua atuação elementos claros de construção da paz. No entanto, ficou ainda aquém em termos dos objetivos de capacitação de recursos humanos, em particular, o que constitui nos dias de hoje um dos desafios centrais à consolidação do Estado. Este enfoque nas instituições não permitiu uma abordagem estrutural à paz, incluindo a dimensão humana como central a todos estes processos. Após a saída da UNMIT em dezembro de 2012, a atual presença mais reduzida, mas também mais específica nos seus objetivos, de um Coordenador Residente das Nações Unidas para assuntos económicos e de desenvolvimento, é muito significativa neste contexto. Demonstra o reconhecimento e a resposta aos pedidos de apoio por parte das autoridades timorenses em matéria 
de capacitação humana e de infraestruturas de base, muito necessárias ao desenvolvimento global do país. O legado da paz técnica parece, deste modo, encontrar abertura para uma maior consolidação de processos estruturais inclusivos, nomeadamente a inserção de dinâmicas locais informais em lógicas formais institucionalizadas. Esta imersão permite que os contornos de uma paz estrutural possam efetivamente ser delineados. Relativamente à questão fundamental da sustentabilidade da paz, a dimensionalidade da mesma assume centralidade, numa perspetiva institucional que é necessária, mas inclusiva em termos de capacitação e respeito por especificidades associadas à realidade local. De notar a questão temporal aqui associada, e que de facto estas são dinâmicas que levam tempo a consolidar-se, devendo ser realçado o percurso e as opções feitas como indicadores positivos no sentido de promoção da paz e estabilidade em Timor-Leste.

\section{Para além do modelo onusiano: modelos combinados ou híbridos}

Esta reflexão permite-nos avançar para além do modelo onusiano de construção de paz na busca de alternativas complementares e mais inclusivas. A manutenção e a consolidação da paz em Timor-Leste resultante da presença das NU foram fundamentais na estabilização da situação de segurança, diminuindo a violência sistematizada, e na construção institucional do Estado, permitindo o funcionamento do aparelho administrativo nas suas três competências fundamentais. Mas como analisado, esta traduz-se numa paz técnica e institucional que não consegue abarcar a multidimensionalidade dos desafios a nível local. Neste quadro, e apesar dos esforços a nível doutrinário no sentido de uma maior articulação entre intervenções e contextos internos, incluindo a dimensão local na sua essência, isto é, tradições e costumes, surgiram propostas de modelos combinados ou híbridos (Mac Ginty, 2010; Richmond, 2011; Freire e Lopes, 2013) que procuram enfatizar a relevância das dinâmicas locais nestes processos (ver neste volume os artigos de Brown; Silva; Pogodda). Estes autores entendem que processos mais inclusivos poderão ajudar a diminuir perceções de alienação e imposição externa e, dessa forma, reforçar lógicas de legitimidade e reconhecimento.

A presença das NU em Timor-Leste permite refletir sobre dois pontos principais: primeiro, tratou-se de uma presença diversa com alguma dificuldade de resposta em momentos específicos, e uma capacidade de articulação com a liderança timorense que se revelou positiva no processo, apesar de ter enfrentado muitos desafios. Segundo, a questão da capacitação local que tem sido referida como uma das grandes críticas à presença das $\mathrm{NU}$, que nunca conseguiram responder efetivamente a este desafio, permanece como linha de base para a formulação de estratégias inclusivas, 
para a qual a concentração num modelo de paz técnica aponta os limites, abrindo ao mesmo tempo novas perspetivas de interpretação da paz e da sua consubstanciação em termos concetuais e no terreno. A retirada da UNMIT permitiu uma alteração muito clara na linguagem e no discurso político timorense, que se assume de forma muito explícita como Estado independente e autónomo, estabilizado e com uma estratégia de crescimento e consolidação voltada para o futuro. Esta imagem é importante em termos das dinâmicas de integração regional e de afirmação de Timor-Leste no plano regional e internacional, visível por exemplo na candidatura do país à Association of Southeast Asian Nations (ASEAN), no assumir da presidência rotativa da Comunidade dos Países de Língua Portuguesa (CPLP) no verão de 2014, ou mesmo no seu estatuto simultâneo de Estado recetor e doador de ajuda pública ao desenvolvimento - relativamente à Guiné-Bissau e a São Tomé e Príncipe, por exemplo. De notar o percurso que o Estado timorense fez em pouco mais de uma década em termos da sua consolidação a nível interno e no plano externo, e para a qual a presença das NU, em diferentes formatos e com capacidade de resposta diferenciada, contribuiu, apesar das dificuldades e dos desafios. A articulação de modelos de paz institucionais com modelos de paz centrados em elementos estruturais onde o indivíduo enquanto agente é o ator central, permite o desenvolvimento de uma paz inclusiva e estruturalmente enraizada. Esta combinação alternativa de modelos de intervenção parece melhor contribuir para a sustentabilidade da paz, recentrando a intervenção das NU numa agenda mais inclusiva.

\section{Organização do número temático}

O presente número temático reflete sobre estas questões centrais à manutenção e construção da paz, aos modelos que têm informado estes processos e a possíveis respostas alternativas, abrindo novas vias de leitura ao nível de políticas e práticas. Organizado numa lógica de especialização, parte de contributos que analisam o intervencionismo em diferentes dimensões e formatos, para se centrar nas NU e na sua atuação em matéria de intervenção, particularizando depois as análises ao caso específico de Timor-Leste. Esta grelha de leitura permite uma análise das políticas e práticas do intervencionismo nas suas várias dimensões, questionando processos e avançando novas possibilidades em termos de atuação, assim como de articulação e definição de políticas. Necla Tschirgi discute os vários entendimentos e abordagens de construção da paz na bibliografia de referência, onde o debate entre as dimensões interna e externa destes mesmos entendimentos e abordagens se reflete nas práticas, ou seja, nos esforços que são desenvolvidos como resposta a situações de pós-violência armada. Alex J. Bellamy foca-se na 
resposta a crises no quadro do princípio da responsabilidade de proteger como um mecanismo que tem permitido delinear as bases de um regime de proteção internacional nestes contextos. Apesar das críticas ao princípio que os casos da Líbia e da Síria sugeriram, o desenvolvimento de um regime de proteção parece estar em curso. Este assenta em pressupostos jurídicos e morais, em novas políticas e práticas de proteção que o Conselho de Segurança tem vindo a definir e adotar, e numa postura crescentemente mais comprometida do Conselho de Segurança com estas matérias, como analisado no artigo.

Nuno Canas Mendes faz uma genealogia do debate em torno da viabilidade do Estado timorense, desde meados da década de 1970 até ao final da presença das Nações Unidas em 2012. O texto contextualiza os debates no contexto histórico específico em que estes se inserem, procurando identificar o posicionamento dos diferentes atores, bem como as suas motivações na construção do Estado timorense. Deste modo, o discurso que acompanha o processo de construção do Estado e da nação é objeto de estudo, permitindo a discussão dos desafios e oportunidades que lhe estão associados neste quadro temporal alargado, contrapondo a agenda política do período da ocupação à agenda política dos atores externos num quadro de intervenção, bem como à agenda interna pós-restauração da independência de Timor-Leste. Aplicando um quadro de análise centrado nos processos de construção democrática, o artigo de Akihisa Matsuno centra-se no mandato da Administração Transitória das Nações Unidas em Timor-Leste e de que modo a sua abordagem focada na consolidação institucional permitiu brechas na construção social e política de Timor-Leste. Deste modo, a análise do legado da missão na sua dimensão democrática e de promoção de diálogo político e social é confrontada com a crise de 2006, onde os limites desta dimensão na construção do Estado timorense se revelam amplos e contribuem para a escalada de violência, dada a limitação em termos de mecanismos de consensualização política para ultrapassar as tensões que emergiram.

Numa abordagem mais específica às problemáticas em estudo, M. Anne Brown remete para a centralidade da dimensão local na construção do Estado timorense, sublinhando a relevância do encontro entre processos de construção do Estado de natureza liberal institucional com formas locais de organização. $\mathrm{O}$ artigo investiga as lógicas diferenciadas que acabam por gerar desafios múltiplos associados às relações entre membros de uma mesma comunidade, decisores e instituições, refletindo espaços de partilha e de silêncio, bem como dinâmicas visíveis e invisíveis de reforço de poder ou de contrapoder, que ora limitam, ora contribuem para o desenvolvimento de processos mais 
inclusivos, assegurando participação alargada. Kelly Silva centra o seu trabatho nos complexos locais de governação na formação do Estado timorense, analisando práticas locais, como o tara bandu, e dinâmicas de estruturação do poder local, no sentido de perceber de que modo lógicas de reconhecimento, incorporação, pacificação e monopolização se revelam fundamentais e estruturantes ao processo. E Sandra Pogodda analisa de que modo as Nações Unidas procuraram incluir nos seus programas de desenvolvimento aspetos culturais locais, identificando tensões face à própria cultura das Nações Unidas e aos procedimentos burocratizados de governação económica. $\mathrm{O}$ (des)ajustamento entre entendimentos face ao local e seus significados e a definição das regras de envolvimento são objeto de análise, como representando dois lados de uma questão de equilíbrios delicados.

Por fim, este volume integra ainda uma entrevista a Roque Rodrigues sobre o processo de construção e consolidação da paz em Timor-Leste, incluindo os desafios que permanecem na agenda e nas ações e refletindo sobre a contribuição de Portugal para a sustentabilidade da paz em Timor-Leste.

Recebido a 21.05.2014

Aprovado para publicação a 29.07.2014

\section{Referências bibliográficas}

Beauvais, Joel (2001), "Benevolent Despotism: A Critique of U.N. State-Building in East Timor”, International Law and Politics, 33, 1101-1178.

Bellamy, Alex; Williams, Paul (2004), "Introduction: Thinking Anew about Peace Operations", International Peacekeeping, 11(1), 1-15.

Boutros-Ghali, Boutros (1992), An Agenda for Peace: Preventive Diplomacy, Peacemaking and Peace-keeping. Report of the Secretary-General pursuant to the statement adopted by the Summit Meeting of the Security Council on 31 January 1992 (A/47/277-S/24111, 17 de junho 1992). Consultado a 06.10.2012, em http://www. un.org/docs/SG/agpeace.html.

Brown, Anne (2011), “The Nation-building Agenda in Timor-Leste”, in Vandra Harris; Andrew Goldsmith (orgs.), Security, Development and nation-Building in Timor-Leste. A Cross-sectoral Assessment. New York: Routledge, 17-37.

Bures, Oldrich (2007), "Wanted: A Mid-Range Theory of International Peacekeeping”, International Studies Review, 9, 407-436.

Cottey, Andrew (2008), "Beyond Humanitarian Intervention: The New Politics of Peacekeeping and Intervention”, Contemporary Politics, 14(4), 429-446.

DeShaw Rae, James (2009), Peacebuilding \& Transitional Justice in East Timor. London:

First Forum Press. 
Doyle, Michael; Sambanis, Nicholas (2006), Making War \& Building Peace. Princeton: Princeton University Press.

Duffield, Mark; Wadell, Nicholas (2004), Human Security and Global Danger: Exploring a Governmental Assemblage. Lancaster: University of Lancaster.

Entrevista a José Ramos-Horta realizada por Maria Raquel Freire, Ramon Blanco, António Leitão e Paula Duarte Lopes (2012), ex-Presidente da República de Timor-Leste, Dili, 1 julho.

Fortna, Virginia Page; Howard, Lise Morjé (2008), "Pitfalls and Prospects in the Peacekeeping Literature", Annual Review of Political Science, 11, 283-301.

Freire, Maria Raquel (no prelo), Consolidação da paz e a sua sustentabilidade: As missões da ONU em Timor-Leste e a contribuição de Portugal. Imprensa da Universidade de Coimbra: Coimbra.

Freire, Maria Raquel; Lopes, Paula Duarte (2013), "Peacebuilding in Timor-Leste: Finding a Way between External Intervention and Local Dynamics”, International Peacekeeping, 20(2), 204-218.

Governo de Timor-Leste (s/d), "História”. Consultado a 22.02.2012, em http://timor-leste.gov.tl/?p=29\&lang=pt.

Machold, Rhys; Donais, Timothy (2011), From Rhetoric to Practice: Operationalizing National Ownership in Post-Conflict Peacebuilding. Workshop Report. New York: Peacebuilding Support Office. Consultado a 06.10.2012, em http://www.un.org/en/ peacebuilding/pbso/pdf/national_ownership_report.pdf.

Mac Ginty, Roger (2010), "Hybrid Peace: The Interaction Between Top-Down and Bottom-Up Peace", Security Dialogue, 41(4), 391-412.

NU - Nações Unidas (1999a), "Question of East Timor. Report of the Secretary-General”, (S/1999/595), 22 maio. New York: Nações Unidas.

NU - Nações Unidas (1999b), CSNU Resolução 1246 (S/RES/1246), 11 de junho. New York: Nações Unidas.

NU - Nações Unidas (1999c), "Report of the Secretary-General on the situation in East Timor" (S/1999/1024), 4 outubro. New York: Nações Unidas.

NU - Nações Unidas (2000), "Report of the Panel on United Nations Peace Operations", (S/2000/809), 21 de agosto. New York: Nações Unidas.

NU - Nações Unidas (2005), CSNU Resolução 1599 (S/RES/1599), 28 de abril. New York: Nações Unidas.

NU - Nações Unidas (2006a), "Letter dated 4 August 2006 from the Chargé d'Affairs a.i. of the Permanent Mission of Timor-Leste to the United Nations addressed to the President of the Security Council, (S/2006/620), 7 de agosto. New York: Nações Unidas. NU - Nações Unidas (2006b), CSNU Resolução 1704 (S/RES/1704), 25 de agosto. New York: Nações Unidas.

NU - Nações Unidas (2008), United Nations Peacekeeping Operations: Principles and Guidelines. New York: United Nations Department of Peacekeeping Operations and Department of Field Support. 
NU - Nações Unidas (2009), "Report of the Secretary-General on Peacebuilding in the Immediate aftermath of Conflict”, (A/63/881-S/2009/304), 11 de junho. New York: Nações Unidas.

O'Neill, John Terence; Rees, Nick (2005), United Nations Peacekeeping in the Post-Cold War Era. New York: Routledge.

Paris, Roland (1997), "Peacebuilding and the Limits of Liberal Internationalism", International Security, 22(2), 54-89.

Paris, Roland; Sisk, Timothy (orgs.) (2009), The Dilemmas of Statebuilding: Confronting the Contradictions of Postwar Peace Operations. New York: Routledge.

Ramsbotham, Oliver; Woodhouse, Tom; Miall, Hugh (2005), Contemporary Conflict Resolution. Cambridge: Polity [2. ${ }^{\mathrm{a}}$ ed.].

Richmond, Oliver (2011), "De-romanticising the Local, De-mystifying the International: Hybridity in Timor Leste and the Solomon Islands", The Pacific Review, 24(1), 115-136.

Smith, Michael G. [com Dee, Moreen] (2003), Peacekeeping in East Timor. The Path to Independence. London: Lynne Rienner Publishers.

Tansey, Oisín (2009), Regime-Building: Democratization and International Administration. Oxford/New York: Oxford University Press.

UNTAET (2002), “UNTAET’s 25 Major Achievements”, Fact Sheet 1, United Nations Transitional Administration in East Timor Press Office, abril de 2002. Consultado a 22.02.2012, em http://www.un.org/en/peacekeeping/missions/past/etimor/fact/ fs01.PDF.

Woodhouse, Tom; Ramsbotham, Oliver (2005), "Cosmopolitan Peacekeeping and the Globalization of Security”, International Peacekeeping, 12(2), 139-156. 
